STUDI

FRANCESI

\section{Studi Francesi}

Rivista quadrimestrale fondata da Franco Simone

170 (LVII | II) | 2013

Varia

\title{
Théophile Gautier, Critique d'art. t. IV. Les Beaux-Arts en Europe - 1855
}

\section{Lise Sabourin}

\section{(2) OpenEdition}

1 Journals

\section{Édition électronique}

URL : https://journals.openedition.org/studifrancesi/3158

DOI : 10.4000/studifrancesi.3158

ISSN : 2421-5856

Éditeur

Rosenberg \& Sellier

\section{Édition imprimée}

Date de publication : 1 juillet 2013

Pagination : 476-477

ISSN : 0039-2944

\section{Référence électronique}

Lise Sabourin, «Théophile Gautier, Critique d'art. t. IV. Les Beaux-Arts en Europe - 1855 », Studi Francesi

[En ligne], 170 (LVII | II) | 2013, mis en ligne le 30 novembre 2015, consulté le 31 janvier 2023. URL:

http://journals.openedition.org/studifrancesi/3158 ; DOI : https://doi.org/10.4000/studifrancesi.3158

Ce document a été généré automatiquement le 31 janvier 2023.

\section{(c) $($ ) (3)}

Creative Commons - Attribution - Pas d'Utilisation Commerciale - Pas de Modification 4.0 International - CC BY-NC-ND 4.0

https://creativecommons.org/licenses/by-nc-nd/4.0/ 


\title{
Théophile Gautier, Critique d'art. $t$. IV. Les Beaux-Arts en Europe - 1855
}

\author{
Lise Sabourin
}

\section{RÉFÉRENCE}

THÉOPHILE GAUTIER, Critique d'art. t. IV. Les Beaux-Arts en Europe - 1855, texte établi, présenté et annoté par Marie-Hélène GIRARD, Paris, Honoré Champion, 2011, pp. 845.

1 Dans l'oubli où est encore tenu le «critique incomparable» (Baudelaire) que fut Gautier en ses Salons de 1833 à 1872, figurait aussi cette analyse des Beaux-Arts en Europe consacrée à la partie picturale de l'Exposition universelle de 1855. Le choix politique essentiel de Napoléon III d'ajouter à la vitrine industrielle cette dimension artistique tendait pourtant à faire de Paris une nouvelle Athènes de l'Europe. Seuls les artistes vivants considérés comme les plus éminents se virent incités à présenter leurs œuvres, ce qui permit à Ingres, Delacroix, Vernet et Decamps d'offrir une rétrospective de leurs tableaux, confrontés ainsi à de plus jeunes, tels Cabanel, Gérôme, Yvon, Chassériau et même Courbet. Tous s'efforcèrent, sauf Ary Scheffer, Eugène Devéria, Paul Delaroche et le sculpteur Préault, de réunir les œuvres les plus marquantes de leur carrière, tandis que les artistes étrangers, sélectionnés par leurs nations, envoyaient également leur production, permettant ainsi une confrontation des écoles. Le jury dut refuser beaucoup d'œuvres vu l'affluence, mais l'exposition présenta mille soixante-douze artistes, par mille huit cent soixante et onze tableaux et trois cent soixante-huit sculptures, dans le Palais des Beaux-Arts, construit spécialement pour cet accrochage, souvent difficile vu la nécessité de superposition due à cet éphémère bâtiment, long et étroit. Un catalogue avec notices, outre le plan-guide pour s'y promener, fut tiré à soixante dix mille exemplaires, totalement vendus au million de visiteurs, dont beaucoup d'étrangers, qui défilèrent durant l'été. Cette effervescence provoqua une saison brillante à l'Opéra et dans les divers théâtres parisiens, soucieux d'attirer cette foule d'amateurs. L'Angleterre et la Prusse furent particulièrement présentes dans l'Exposition picturale, plus que l'Italie éclatée sous le joug autrichien, mais des peintres 
de toutes nationalités firent le voyage, rencontrant les français eux aussi fascinés par les occasions suscitées (Degas jeune entre ainsi en relations avec Ingres, Pissarro découvre Corot).

Dans l'immense activité de la critique d'art, dont Marie-Hélène Girard, l'éditrice critique de ce beau volume, dresse le panorama (pp. 32-34), Gautier, critique attitré de «La Presse» depuis 1836, tient évidemment une place exceptionnelle par ses chroniques du 15 mai au 30 novembre 1855 au «Moniteur», où il était entré depuis 1853 après le décès de Delphine de Girardin et par besoin financier. Son autorité incontestée d'agnostique ne le rendait pas esclave du point de vue étatique, d'ailleurs moins hostile qu'on ne l'a longtemps dit à la nouveauté. Sans complaisance ni conformisme, son appréciation des artistes se fonde sur leur originalité, et il sait nuancer sur les œuvres qui pourraient prêter à interprétation politique comme Le Siècle d'Auguste de Gérôme face aux Romains de la décadence de Couture. Sa conviction sur la primauté de l'école française remonte à loin, tout en restant sobre par rapport aux discours officiels qui liaient l'art au progrès industriel. Évitant de mentionner les récompenses obtenues par certains artistes dont il analyse les œuvres, il marque son indépendance par son intérêt pour des artistes républicains ou laïcs, par ses allusions à Hugo ou Stendhal. La défense des animaux contre les brutalités des hommes est une autre de ces «idées secrètes» que Gautier aime à suggérer à ses lecteurs, dénonçant la loi des plus forts sur les faibles.

Plutôt que de voir dans le passage de Gautier au «Moniteur» une allégeance au régime, Marie-Hélène Girard démontre qu'il a su, sous sa bénignité, préserver son libre-arbitre et l'intégrité de ses convictions esthétiques. Les contraintes éditoriales ont sans doute été plus pesantes: menant de front sa critique dramatique en cette saison exceptionnelle, Gautier peine sous le rythme de son double feuilleton hebdomadaire, obligé par l'accélération à emprunter quelquefois des citations au catalogue. La publication de ce Salon plus volumineux que les autres révèle certains détails de son plan initial, qui a dû trouver ensuite des compromis entre compte rendu et anthologie, et explique les modifications opérées entre les parutions en feuilleton et en volume, tant leur auteur était pris dans «la meule du journalisme». Resté fidèle au romantisme, Gautier en perçoit bien l'évolution (de la flamme coloriste et passionnelle à l'exotisme oriental ou historique) et s'ouvre à l'éclectisme ambiant. Sa volonté de rendre justice à la diversité des talents le rend sensible à la nouveauté des paysagistes de plein air (Corot, l'école de Barbizon); mais, toujours idéaliste, il préfère le beau d'héritage goethéen (chez Ingres) au réalisme du quotidien (ainsi loue-t-il la rusticité de Millet alors qu'il voit chez Courbet l'exaltation de la laideur). Il reconnaît cependant le réalisme quasi balzacien des scènes de genre anglaises, tout en montrant son intérêt pour les préraphaélites. Gautier est très attentif à la réalisation technique des œuvres, la forme maîtrisée manifestant le «microcosme intérieur» de chaque artiste.

4 Nous devons beaucoup à Marie-Hélène Girard qui nous permet d'accéder, en une édition annotée avec érudition, munie d'une riche bibliographie et d'un index des noms des artistes essentiel à la circulation dans cet important corpus, à cette œuvre qui constitue «une date mémorable» (selon le titre de sa précieuse préface, pp. 11-92) pour l'art français comme dans la pensée esthétique du critique qui allait devenir le directeur de «L'Artiste» en 1866. 